\title{
CCND1 copy number increase and cyclin D1 expression in acral melanoma: a comparative study of fluorescence in situ hybridization and immunohistochemistry in a Chinese cohort
}

Jianying Liu', Wenjuan Yu², Fei Gao ${ }^{1}$, Shuangshuang $\mathrm{Qi}^{1}$, Juan Dư ${ }^{1}$ Xiaolong Ma', Yan Zhang ${ }^{1}$, Jie Zheng ${ }^{1}$ and Jing $\mathrm{Su}^{1 *}$ (D)

\begin{abstract}
Background: CCND1 copy number increase is characteristic of acral melanoma and is useful in distinguishing benign and malignant acral melanocytic lesions. Increase of the gene copy number may result in protein overexpression. This raises the possibility that detection of high expression of cyclin D1 by immunohistochemistry $(\mathrm{HC})$ may be used as a surrogate for direct evaluation of increase in the CCND1 gene copy number.

Methods: We examined increases in CCND1 copy number with fluorescence in situ hybridization (FISH), and examined cyclin D1 protein expression with IHC in 61 acral melanomas.
\end{abstract}

Results: Using FISH, 29 acral melanomas (29/61, 47.5\%) showed increase in the CCND1 copy number, including 8 $(8 / 61,13.1 \%)$ which showed low-level increase in the CCND1 copy number and 21 (21/61, 34.4\%) with high-level increase in the CCND1 copy number. By analysis of IHC, the median IHC score was 15\% (range: 1-80\%) in acral melanomas with no CCND1 copy number alteration. In acral melanomas with low-level CCND1 copy number increase, the median IHC score was 25\% (range: 3-90\%). In acral melanomas with high-level CCND1 copy number increase, the median IHC score was 60\% (range: 1-95\%). Comparing FISH and IHC, cyclin D1 protein expression level has no corelation with the CCND1 copy number in acral melanomas which have no CCND1 copy number alteration and low-level CCND1 copy number increase $(P=0.108)$. Cyclin D1 protein expression level correlated positively with CCND1 copy number in acral melanomas with high-level CCND1 copy number increase $(P=0.038)$. The sensitivity, specificity and positive predictive value of using cyclin D1 IHC to predict CCND1 FISH result was 72.4, 62.5 and $63.6 \%$. Increase in CCND1 copy number was associated with Breslow thickness in invasive acral melanoma.

\footnotetext{
* Correspondence: sujing@bjmu.edu.cn

'Department of Pathology, School of Basic Medical Sciences, Third Hospital, Peking University Health Science Center, 38 Xueyuan Road, Beijing 100191, China

Full list of author information is available at the end of the article
}

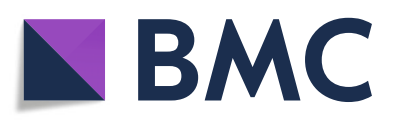

(- The Author(s). 2021 Open Access This article is licensed under a Creative Commons Attribution 4.0 International License, which permits use, sharing, adaptation, distribution and reproduction in any medium or format, as long as you give appropriate credit to the original author(s) and the source, provide a link to the Creative Commons licence, and indicate if changes were made. The images or other third party material in this article are included in the article's Creative Commons licence, unless indicated otherwise in a credit line to the material. If material is not included in the article's Creative Commons licence and your intended use is not permitted by statutory regulation or exceeds the permitted use, you will need to obtain permission directly from the copyright holder. To view a copy of this licence, visit http://creativecommons.org/licenses/by/4.0/. The Creative Commons Public Domain Dedication waiver (http://creativecommons.org/publicdomain/zero/1.0/) applies to the data made available in this article, unless otherwise stated in a credit line to the data. 
Conclusion: High-level increase in the CCND1 copy number can induce high cyclin D1 protein expression in acral melanomas. However low-level increase and normal CCND1 copy number have no obvious correlation with protein expression. Cyclin D1 IHC cannot serve as a surrogate for CCND1 FISH in acral melanomas.

Keywords: CCND1 (cyclin D1), Acral melanoma, Gene copy number increase, Protein expression

\section{Introduction}

Acral melanoma is a distinct subtype of melanoma that most commonly affects the Asian population and has worse survival than other cutaneous melanomas [1, 2]. Acral melanoma may be particularly difficult to distinguish from acral nevus by histopathology, and ancillary methods that help establish the diagnosis may be useful. The CCND1 gene which is located on chromosome 11q13 is a protooncogene which is transcribed to protein cyclin D1, and cyclin D1 forms active complexes with CDK4/CDK6, resulting in phosphorylation of the retinoblastoma protein $(\mathrm{Rb})$ which drives $\mathrm{G} 1$ to $\mathrm{S}$ phase [3]. Abnormalities of the CCND1 gene are found in some malignant melanocytic tumors, and especially in acral melanoma $[4,5]$. In acral melanoma, most CCND1 abnormalities are characterized by an increase of the gene copy number, and CCND1 copy number changes are not found in acral melanocytic nevi $[5,6]$. A fluorescence in situ hybridization (FISH) panel including CCND1 has proved to be an effective means of distinguishing benign and malignant melanocytic tumors, including acral melanocytic tumors [7-13].

Gene copy number increase in cancer-promoting driver gene in malignant cells may result in protein overexpression, such as in human epithelial growth receptor 2 (HER2) on chromosome 17 [14]. In breast cancer and gastric cancer, there is good correlation in HER2 gene copy number increase and protein overexpression, which allows use of immunohistochemistry (IHC) in these tumors as a method for preliminary screening before resorting to FISH $[15,16]$. We wished to determine whether increases in CCND1 gene copy number and cyclin D1 protein expression is correlated in acral melanoma. If so, IHC has potential to serve as a preliminary screening method which is both easier technically and more economical than FISH.

The aim of this study was to evaluate the consistency of CCND1 copy number increase with cyclin D1 protein expression in acral melanomas, and to assess the potential role of cyclin D1 IHC serving as a preliminary screening method for CCND1 FISH. For this purpose, we evaluated 61 acral melanomas for $C C N D 1$ copy number alteration and cyclin D1 expression.

\section{Materials and methods}

\section{Patients}

A total of 61 successive and unselected cases of acral melanoma were collected from the Department of
Pathology, School of Basic Medical Sciences, Third Hospital, Peking University Health Science Center from January 2013 to October 2018. In addition to these 61 acral melanomas, 26 benign acral melanocytic nevi were also collected and evaluated. All specimens were fixed in formalin and embedded in paraffin. Two pathologists (Jianying Liu and Jing $\mathrm{Su}$ ) read these cases independently to confirm the diagnoses. This study was approved by the Research Ethics Committee, Peking University Health Science Centre, Beijing, China.

\section{Fluorescence in situ hybridization and signal measurement}

CCND1 FISH analysis was conducted as previously described using the Vysis Melanoma FISH Probe Kit purchased from Abbott Molecular Inc. (Des Plaines, IL, USA) [8]. After hybridization, FISH slides were screened at high magnification ( $\times 100$ objective with oil immersion). A total of 30 non-overlapping intact tumor nuclei were counted for each slide. The average copy number for the CCND1 gene site was calculated.

When the average copy number for CCND1 was $\geq 2.50$, the tumor was considered to have an increase in $C C N D 1$ copy number. When the average copy number of $C C N D 1$ was $\geq 2.50$ but $<4.00$, the tumor was classified as having a low-level increase in CCND1 copy number; and when the average copy number of CCND $1 \geq 4.00$, the tumor was considered to have a high-level increase in $C C N D 1$ copy number.

Immunohistochemistry and evaluation of immunostaining Cyclin D1 IHC was performed with a LEICA BONDMAX system using Cyclin D1 Rabbit monoclonal antibody (Cell Marque, California, USA). The percentage of positive cells (nuclear staining) was scored by two pathologists (Jianying Liu and Jing $\mathrm{Su}$ ) who were blinded to the FISH results. The average score generated by these two pathologists was used as the final IHC score.

\section{Statistical analysis}

The intraclass correlation coefficient of the IHC scores for Jianying Liu and Jing Su was calculated. The intraclass correlation coefficient of the IHC scores generated by the two pathologists (Jianying Liu and Jing $\mathrm{Su}$ ) was above $90 \%$. The Bland Altman plot (Fig. 1) shows the difference mean between the two pathologists is $0.8 \%$, the standard deviation (SD) is $5.4 \%$ and the range 


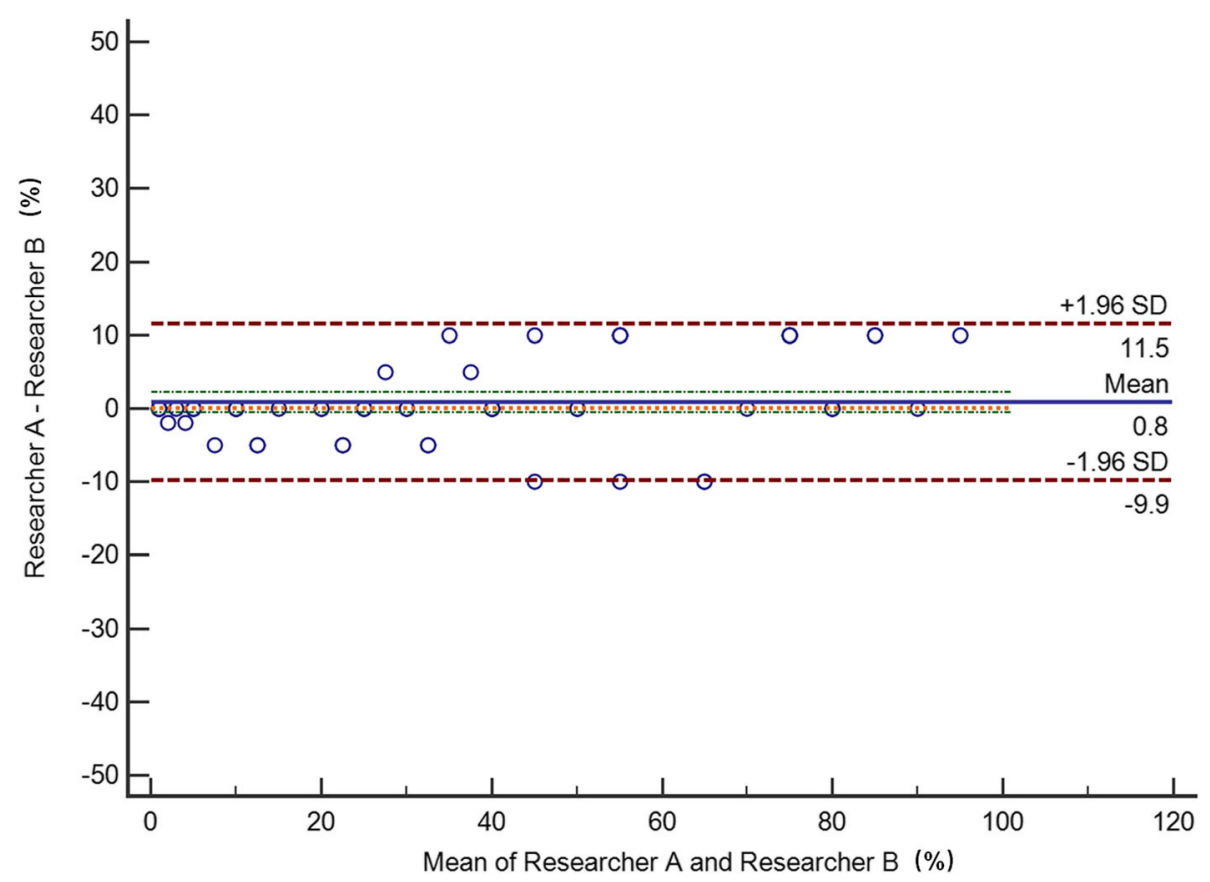

Fig. 1 Bland Altman plot for the cyclin D1 IHC score by the two pathologists (Jianying Liu and Jing Su)

between difference mean $\pm 1.96 \mathrm{SD}$ is from -9.9 to $11.5 \%$. These imply that there is good agreement between the two pathologists. The average score for these two pathologists was used as the final IHC score.

The correlation between the CCND1 gene copy number and cyclin D1 protein expression was evaluated with Spearman correlation. The most effective cut-off score for cyclin D1 IHC (percentage of positive cells) for predicting FISH results was calculated with ROC curves. The specificity, sensitivity, positive predictive value and negative predictive value of using cyclin D1 IHC scores to predict CCND1 FISH results was calculated with binary logistic regression and ROC curve. The relationship of CCND1 gene copy number alterations and patient gender, as well as tumor ulceration was assessed with the Pearson's chisquare $x^{2}$ test. The relationship of the CCND1 gene copy number alterations and other clinicopathologic parameters (patient age, Breslow thickness and Clark's level) were assessed with the independent $\mathrm{T}$ test. The relationship of cyclin D1 expression status and patient gender, as well as tumor ulceration were assessed with nonparametric tests. The relationship of cyclin D1 expression status and other clinicopathologic parameters (patient age, Breslow thickness and Clark's level) were assessed with Spearman correlation. All statistical data were calculated using IBM SPSS statistics 23 (USA). All $p$ values were two-sided. $P$ values $<0.05$ were considered statistically significant.

\section{Results}

\section{Clinicopathologic characteristics}

The clinical and pathologic features of the 61 acral melanoma patients evaluated in this study are summarized in Table 1. Thirty-two melanoma patients were male and 29 were female (male-to-female ratio 1.1:1). The median patient age was 62 years with a range of 22 to 87 years. Histologic subtypes included acral lentiginous melanoma (43/61, 70.5\%) and nodular melanoma (18/61, 29.5\%). The mean Breslow thickness was $4.3 \mathrm{~mm}$ (range $0.5 \mathrm{~mm}$ to $30.0 \mathrm{~mm}$ ). Ulceration was observed in 27 cases $(27 / 61,44.3 \%)$.

A total of 26 benign acral melanocytic nevi from 12 male and 14 female patients of ages 5 to 58 years (median age 29) were evaluated. These nevi were all of conventional type, and included 15 compound nevi and 11 intradermal nevi. The sites included palm $(5 / 26,19.2 \%)$ and sole $(21 / 26,80.8 \%)$.

\section{CCND1 copy number alteration in acral melanomas}

Thirty-two acral melanomas $(52.5 \%, 32 / 61)$ showed no CCND1 copy number alterations (Fig. $2 \mathrm{~b}$ and e). Twenty-nine acral melanomas $(47.5 \%, 29 / 61)$ showed increased CCND1 copy number. Eight of these (8/61, $13.1 \%)$ showed low-level copy number increase (average copy number $\geq 2.5$ and $<4.0$, Figs. $3 \mathrm{~b}$ and e) and $21(21 / 61,34.4 \%)$ showed high-level copy number increase (average copy number $\geq 4.0$, Fig. $4 \mathrm{~b}$ and e). 
Table 1 Clinical and pathological features of the acral melanoma patients (61 cases)

\begin{tabular}{ll}
\hline Feature & Number of patients (\%) \\
\hline Gender & \\
Male & $32(52.5 \%)$ \\
Female & $29(47.5 \%)$ \\
Age at surgery (years) & \\
Median age & 62 \\
Range & $(22-87)$ \\
Site & \\
Foot & $39(63.9 \%)$ \\
Hand & $17(27.9 \%)$ \\
Nail & $5(8.2 \%)$ \\
Histological subtype & \\
Acral-lentigous melanoma & $43(70.5 \%)$ \\
Nodular melanoma & $18(29.5 \%)$ \\
Breslow thickness & \\
$\leq 1$ mm & $11(18.0 \%)$ \\
$>1.0$ mm-2.0 mm & $17(27.9 \%)$ \\
$>$ 2.0 mm-4.0 mm & $16(26.2 \%)$ \\
$>$ V.0 mm & $17(27.9 \%)$ \\
Mean tumor thickness (mm) & 4.3 \\
Median tumor thickness (mm) & 2.5 \\
Ulceration & $37(60.7 \%)$ \\
Yes & \\
III & $34(5.8 \%)$ \\
\hline
\end{tabular}

\section{Cyclin D1 expression in acral melanomas}

Nuclear cyclin D1 expression was found in all 61 acral melanomas using IHC. The median IHC score in acral melanoma was 30\% (range: 1-95\%). In acral melanomas with no CCND1 copy number alteration, the median IHC score was 15\% (range: 1-80\%) (Fig. 2c and f). In acral melanomas with low-level CCND1 copy number increase, the median IHC score was 25\% (range: 3-90\%) (Fig. 3c and f). In acral melanomas with high-level CCND1 copy number increase, the median IHC score was $60 \%$ (range: 1-95\%) (Fig. 4c and f). The median IHC score for acral nevi was $10 \%$ (range: $1-30 \%$ ).

Comparison of CCND1 copy number alteration and cyclin D1 protein expression in acral melanomas

The correlation of CCND1 gene copy number and cyclin D1 protein expression is shown in Fig. 5. The cyclin D1 protein expression level has no corelation with CCND1 copy number in acral melanomas with no CCND1 copy number alteration and low-level copy number increase $(P=0.108)$. The cyclin D1 protein expression level correlates positively with the CCND1 copy number in acral melanomas with high-level CCND1 copy number increase $(P=0.038)$.

\section{Using cyclin D1 IHC score to predict CCND1 FISH result} Using ROC curves, we found that $27.5 \%$ is the most effective cyclin D1 IHC cut-off for predicting CCND1 FISH results, with a sensitivity of $72.4 \%$ and a specificity of $62.5 \%$. The positive predictive value is $63.6 \%$ and negative predictive value is $71.4 \%$. The cyclin D1 IHC score does not predict CCND1 copy number alterations properly.

\section{Correlation of FISH and IHC results with clinicopathologic characteristics}

CCND1 copy number increase is associated with the Breslow thickness $(P=0.043)$ in invasive acral melanomas. There were no CCND1 copy number changes associated with other clinicopathologic parameters under evaluation, including patient age $(P=0.128)$, gender $(P=0.509)$, ulceration $(P=0.815)$, or Clark's level $(P=0.887)$. Furthermore, there was no evidence of association of cyclin D1 expression with these clinicopathologic parameters, including patient age $(P=0.114)$, gender $(P=0.358)$, Breslow thickness $(P=0.990)$, ulceration $(P=0.198)$, and Clark's level $(P=0.661)$.

\section{Discussion}

In this study, we aimed to explore the relationship of CCND1 copy number alteration and cyclin D1 protein expression in acral melanoma, and to determine whether anti-cyclin D1 IHC may be used as a surrogate for direct evaluation of increase in CCND1 copy number. Our results show high-level CCND1 copy number increase has good correlation with cyclin D1 protein expression in acral melanoma. However low-level copy number increases do not show correlation with protein expression in acral melanoma. The sensitivity (72.4\%), specificity $(62.5 \%)$ and positive predictive value (63.6\%) of using the IHC score to predict FISH results are not good. Cyclin D1 IHC therefore cannot be used as a surrogate for direct evaluation of increase in CCND1 copy number. Our results are consistent with the possibility CCND1 copy number increase induce high cyclin D1 expression and promote progression in acral melanomas with highlevel CCND1 copy number increase. However, for acral melanoma with low-level CCND1 copy number increase, copy number increase is most likely merely a result of genetic instability which occurs during tumor progression and does not induce increase in protein expression [17]. 

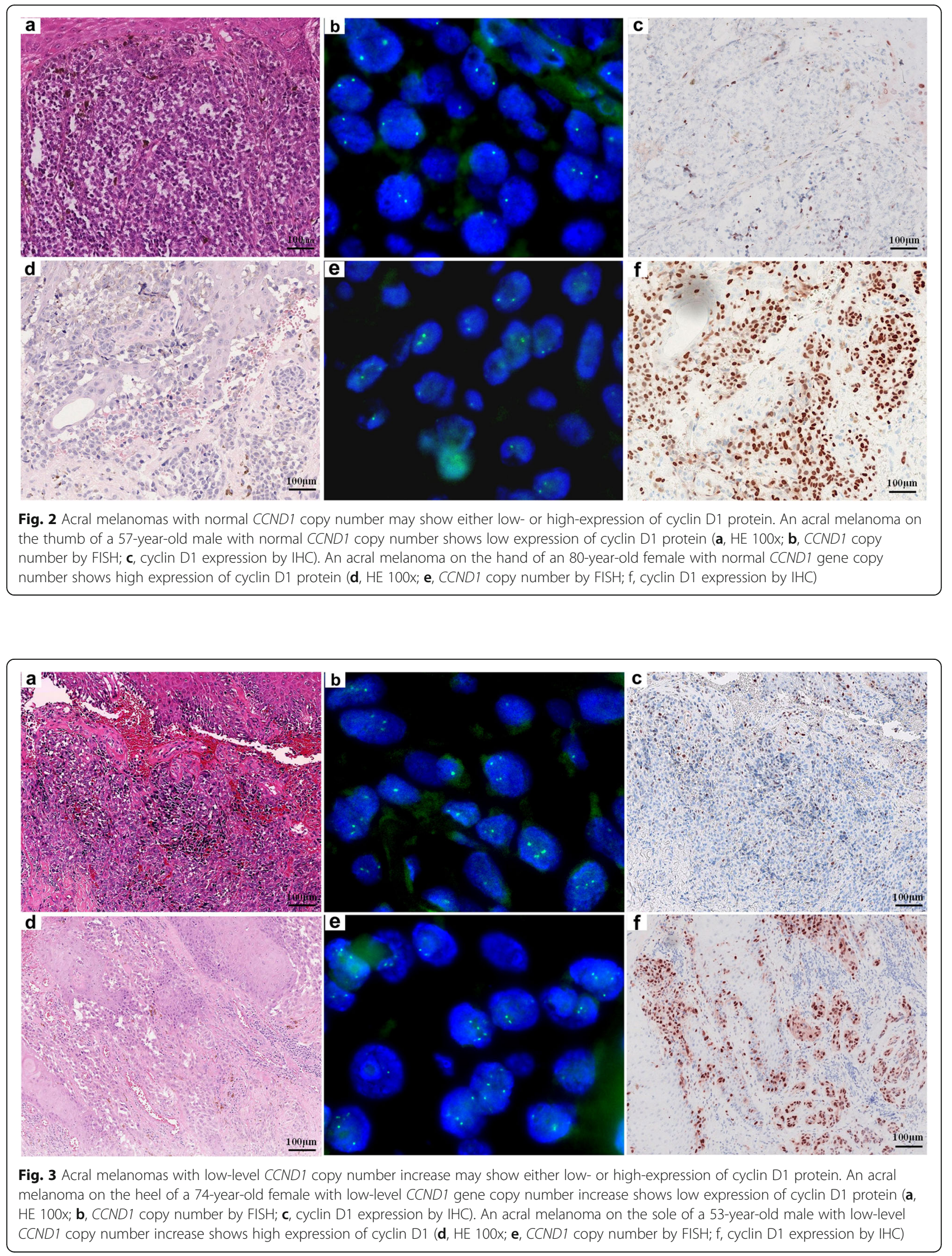

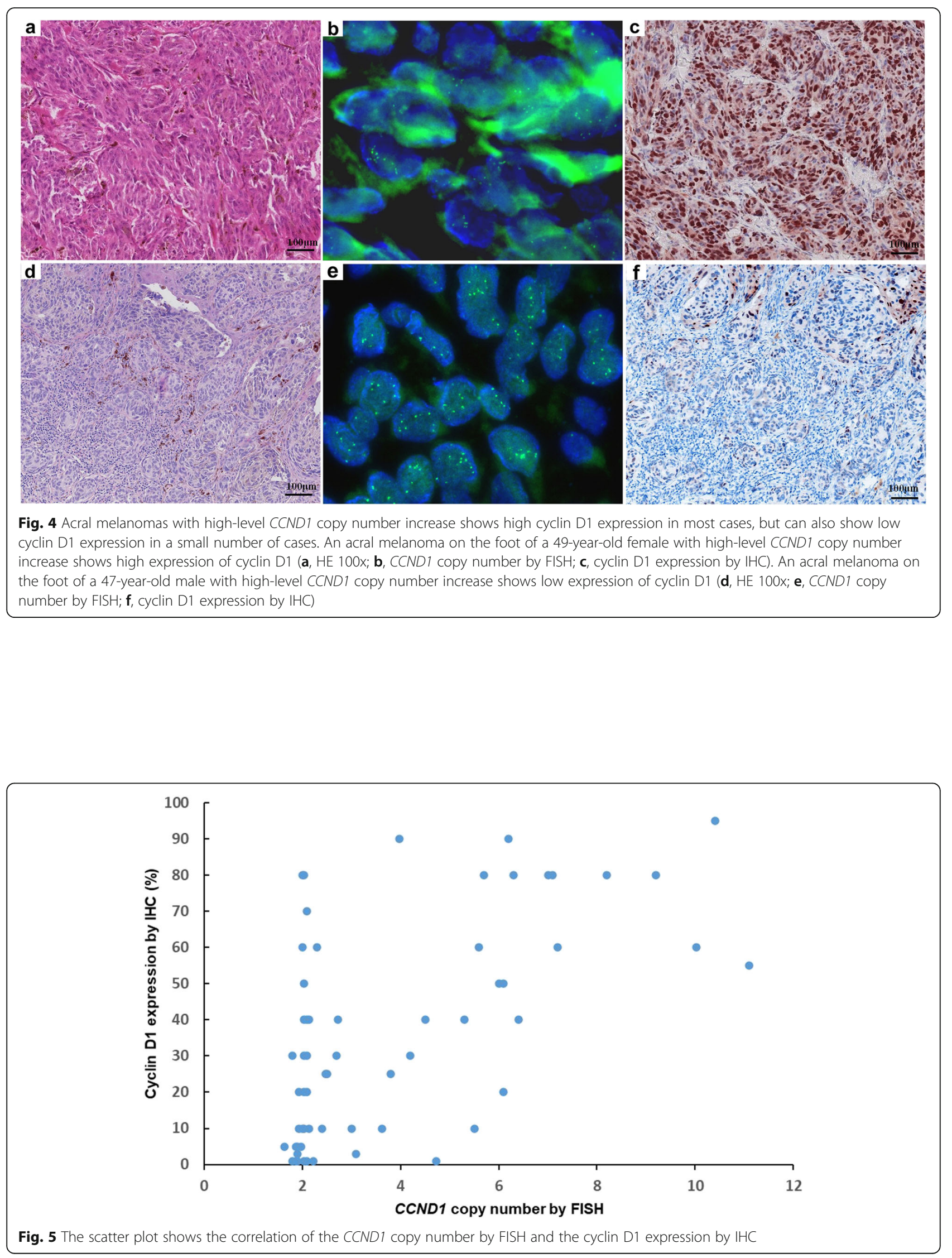
Acral melanoma is the main subtype of melanoma which affects Asian population and this melanoma subtype occurs in glabrous acral skin such as on the palms, soles, and on the nail apparatus [18]. The genomics of acral melanoma are distinct from melanoma from other cutaneous sites [19]. CCND1 copy number increase is known to occur more commonly in acral melanomas than in melanomas in other cutaneous sites [20-24]. However the sensitivity of CCND1 FISH for evaluation of acral melanocytic tumors is not high, and this relatively low sensitivity may result from the high heterogeneity of melanoma [25]. Both whole-genome mutation landscape and targeted genomic profiling studies demonstrate diverse oncogenic processes and genetic alterations in acral melanomas $[20,21]$.

In our cohort as many as $37.5 \%(12 / 32)$ cases without CCND1 gene copy number increase showed high cyclin D1 protein expression, similar to the findings in a previous study [5]. In the absence of DNA copy number increase, gene overexpression may result from other mechanisms [14]. Factors other than copy number including transcriptional, post-transcriptional and translational regulation may influence cyclin D1 expression in melanoma $[3,26]$. At this time we do not know the exact mechanism of high cyclin D1 expression in absence of an increased CCND1 copy number in acral melanoma. This will be explored in our future research.

It is also noteworthy that in our cyclin D1 high-level copy number increase group, three cases $(3 / 21,19.0 \%)$ showed low protein expression. Cyclin D1 protein expression is regulated by a complex network, and the mechanism by which low protein expression occurs in the context of high-level increase in gene copy number is unknown. In tumors with low-level CCND1 copy number increase, five cases $(5 / 8,62.5 \%)$ showed low protein expression. This indicates that low-level CCND1 copy number increase does not lead to increase in protein expression in most cases. The copy number increase may be caused by polyploidy. When the CCND1 copy number change is interpreted, it should be expressed in relation to one or more of the other FISH probes used.

In our cohort we found that CCND1 copy number increase was associated with the Breslow thickness in invasive acral melanomas. That is, when invasive acral melanoma shows CCND1 copy number increase the tumor will be thicker. This observation suggests that CCND1 alterations may be linked to acral melanoma progression and have prognostic relevance in acral melanomas. Breslow thickness is in general the most important parameter for determining prognosis in melanoma. In our cohort some cases were consultation cases for which we failed to obtain information such as nodal status and overall survival which are more directly correlated with prognosis. We recognize this is a limitation of this study.
In summary, we found that in acral melanomas with high-level CCND1 copy number increase IHC correlates well with FISH, while in cases with low-level CCND1 copy number increase or no CCND1 copy number alteration, no correlation was found. Using cyclin D1 IHC to predict CCND1 copy number changes which can be detected by FISH is not reliable. Our findings suggested that IHC is not feasible as a surrogate for direct evaluation of CCND1 gene copy number alteration.

\section{Abbreviations}

FISH: Fluorescence in situ hybridization; IHC: Immunohistochemistry

\section{Acknowledgements}

We are grateful to the Department of Pathology, School of Basic Medical Sciences, Third Hospital, Peking University Health Science Center for excellent working conditions and for providing access to archival materials.

\section{Authors' contributions}

JS, JL: study design; FG, JD, XM, YZ: immunohistochemistry; SQ: fluorescence in situ hybridization; JS, WY: data analysis and statistical analysis; JS, JL, JZ: manuscript preparation and editing. All authors read and approved the final manuscript.

\section{Funding}

This work was supported by National Natural Science Foundation of China (Grant number: 81802245).

\section{Availability of data and materials}

The data are available from the corresponding author upon reasonable request.

\section{Declarations}

Ethics approval and consent to participate

This study received approval from the Ethics Committee of the Research Ethics Committee, Peking University Health Science Centre. Additional informed consent was not required by the ethics committee for this retrospective study.

\section{Consent for publication}

Not applicable.

\section{Competing interests}

The authors declare that they have no competing interests.

\section{Author details}

${ }^{1}$ Department of Pathology, School of Basic Medical Sciences, Third Hospital, Peking University Health Science Center, 38 Xueyuan Road, Beijing 100191, China. ${ }^{2}$ Department of Pathology, The Affiliated Hospital of Qingdao University, Qingdao 266003, China.

Received: 14 February 2021 Accepted: 7 June 2021

Published online: 05 July 2021

\section{References}

1. Durbec F, Martin L, Derancourt C, Grange F. Melanoma of the hand and foot: epidemiological, prognostic and genetic features. A systematic review. Br J Dermatol. 2012;166(4):727-39. https://doi.org/10.1111/j.1365-2133.2011.1 0772.x.

2. Bello DM, Chou JF, Panageas KS, Brady MS, Coit DG, Carvajal RD, et al. Prognosis of acral melanoma: a series of 281 patients. Ann Surg Oncol. 2013;20(11):3618-25. https://doi.org/10.1245/s10434-013-3089-0.

3. Qie S, Diehl JA. Cyclin D1, cancer progression, and opportunities in cancer treatment. J Mol Med. 2016;94(12):1313-26. https://doi.org/10.1007/s00109016-1475-3.

4. Musgrove EA, Caldon CE, Barraclough J, Stone A, Sutherland RL. Cyclin D as a therapeutic target in cancer. Nat Rev Cancer. 2011;11(8):558-72. https:// doi.org/10.1038/nrc3090. 
5. Sauter ER, Yeo UC, von Stemm A, Zhu W, Litwin S, Tichansky DS, et al. Cyclin D1 is a candidate oncogene in cutaneous melanoma. Cancer Res. 2002;62(11):3200-6.

6. Kong Y, Sheng X, Wu X, Yan J, Ma M, Yu J, et al. Frequent genetic aberrations in the CDK4 pathway in Acral melanoma indicate the potential for CDK4/6 inhibitors in targeted therapy. Clin Cancer Res. 2017;23(22):694657. https://doi.org/10.1158/1078-0432.CCR-17-0070.

7. Ferrara G, De Vanna AC. Fluorescence in situ hybridization for melanoma diagnosis: a review and a reappraisal. Am J Dermatopathol. 2016;38(4):25369. https://doi.org/10.1097/DAD.0000000000000380.

8. Su J, Yu W, Liu J, Zheng J, Huang S, Wang Y, et al. Fluorescence in situ hybridisation as an ancillary tool in the diagnosis of acral melanoma: a review of 44 cases. Pathology. 2017;49(7):740-9. https://doi.org/10.1016/j.pa thol.2017.08.006

9. Gerami P, Jewell SS, Morrison LE, Blondin B, Schulz J, Ruffalo T, et al. Fluorescence in situ hybridization (FISH) as an ancillary diagnostic tool in the diagnosis of melanoma. Am J Surg Pathol. 2009;33(8):1146-56. https:// doi.org/10.1097/PAS.0b013e3181a1ef36.

10. Gerami P, Li G, Pouryazdanparast P, Blondin B, Beilfuss B, Slenk C, et al. A highly specific and discriminatory FISH assay for distinguishing between benign and malignant melanocytic neoplasms. Am J Surg Pathol. 2012; 36(6):808-17. https://doi.org/10.1097/PAS.0b013e31824b1efd.

11. Kerl K, Palmedo G, Wiesner T, Mentzel T, Rutten A, Scharer L, et al. A proposal for improving multicolor FISH sensitivity in the diagnosis of malignant melanoma using new combined criteria. Am J Dermatopathol. 2012;34(6):580-5. https://doi.org/10.1097/DAD.0b013e3182433f3a.

12. North JP, Garrido MC, Kolaitis NA, LeBoit PE, McCalmont TH, Bastian BC. Fluorescence in situ hybridization as an ancillary tool in the diagnosis of ambiguous melanocytic neoplasms: a review of 804 cases. Am J Surg Pathol. 2014;38(6):824-31. https://doi.org/10.1097/PAS. 0000000000000189.

13. Lai $Y, W u ~ Y$, Liu R, Lu A, Zhou L, Jia L, et al. Four-color fluorescence in-situ hybridization is useful to assist to distinguish early stage acral and cutaneous melanomas from dysplastic junctional or compound nevus. Diagn Pathol. 2020;15(1):51. https://doi.org/10.1186/s13000-020-00937-9.

14. Santarius T, Shipley J, Brewer D, Stratton MR, Cooper CS. A census of amplified and overexpressed human cancer genes. Nat Rev Cancer. 2010; 10(1):59-64. https://doi.org/10.1038/nrc2771.

15. Krishnamurti U, Silverman JF. HER2 in breast cancer: a review and update. Adv Anat Pathol. 2014;21(2):100-7. https://doi.org/10.1097/PAP. 0000000000000015 .

16. Silva MR, Alarcao A, Ferreira T, d'Aguiar M, Ladeirinha A, Balseiro S, et al. Evaluation of HER2 by automated FISH and IHC in gastric carcinoma biopsies. Int J Biol Markers. 2016;31(1):e38-43. https://doi.org/10.5301/jbm. 5000169.

17. Vogelstein B, Papadopoulos N, Velculescu VE, Zhou S, Diaz LA Jr, Kinzler KW. Cancer genome landscapes. Science. 2013;339(6127):1546-58. https://doi. org/10.1126/science.1235122.

18. Chi ZH, Li SM, Sheng XN, Si L, Cui CL, Han M, et al. Clinical presentation, histology, and prognoses of malignant melanoma in ethnic Chinese: a study of 522 consecutive cases. BMC Cancer. 2011;11(1). https://doi.org/1 0.1186/1471-2407-11-85.

19. Rabbie R, Ferguson P, Molina-Aguilar C, Adams DJ, Robles-Espinoza CD. Melanoma subtypes: genomic profiles, prognostic molecular markers and therapeutic possibilities. J Pathol. 2019;247(5):539-51. https://doi.org/10.1 002/path.5213.

20. Hayward NK, Wilmott JS, Waddell N, Johansson PA, Field MA, Nones K, et al. Whole-genome landscapes of major melanoma subtypes. Nature. 2017; 545(7653):175-80. https://doi.org/10.1038/nature22071.

21. Yeh I, Jorgenson E, Shen L, Xu MS, North JP, Shain AH, et al. Targeted genomic profiling of Acral melanoma. JNCI. 2019;111(10):1068-77. https:// doi.org/10.1093/jnci/djz005.

22. Glatz-Krieger K, Pache M, Tapia C, Fuchs A, Savic S, Glatz D, et al. Anatomic site-specific patterns of gene copy number gains in skin, mucosal, and uveal melanomas detected by fluorescence in situ hybridization. Virchows Arch. 2006;449(3):328-33. https://doi.org/10.1007/s00428-006-0167-8.

23. Curtin JA, Fridlyand J, Kageshita T, Patel HN, Busam KJ, Kutzner H, et al. Distinct sets of genetic alterations in melanoma. New Engl J Med. 2005; 353(20):2135-47. https://doi.org/10.1056/NEJMoa050092.

24. Takata M, Goto Y, Ichii N, Yamaura M, Murata H, Koga H, et al. Constitutive activation of the mitogen-activated protein kinase signaling pathway in acral melanomas. J Invest Dermatol. 2005;125(2):318-22. https://doi.org/1 0.1111/j.0022-202X.2005.23812.x.

25. Shannan B, Perego M, Somasundaram R, Herlyn M. Heterogeneity in Melanoma. Cancer Treat Res. 2016;167:1-15. https://doi.org/10.1007/ 978-3-319-22539-5_1.

26. Chen J, Feilotter HE, Pare GC, Zhang X, Pemberton JG, Garady C, et al. MicroRNA-193b represses cell proliferation and regulates cyclin D1 in melanoma. Am J Pathol. 2010;176(5):2520-9. https://doi.org/10.2353/ajpath.2 010.091061.

\section{Publisher's Note}

Springer Nature remains neutral with regard to jurisdictional claims in published maps and institutional affiliations.
Ready to submit your research? Choose BMC and benefit from:

- fast, convenient online submission

- thorough peer review by experienced researchers in your field

- rapid publication on acceptance

- support for research data, including large and complex data types

- gold Open Access which fosters wider collaboration and increased citations

- maximum visibility for your research: over $100 \mathrm{M}$ website views per year

At BMC, research is always in progress.

Learn more biomedcentral.com/submissions 